\title{
The influence of heartwood, sapwood and density on moisture fluctuations and crack formations of coated Norway spruce in outdoor exposure
}

\author{
T. Sjökvist ${ }^{*} \mathbb{D}, \AA$. Blom ${ }^{1}$ and M. E. P. Wålinder ${ }^{2}$
}

\begin{abstract}
The moisture sorption behaviour of wood strongly influences the durability of exterior-coated wood. Wood characteristics are known to influence the water sorption of uncoated wood. Despite this, the majority of the research on coated wood has been focused on the coating properties. This study aims to investigate the impact of heartwood, sapwood and density on the moisture content (MC) and crack formation of coated Norway spruce (Picea abies (L.) Karst.). Boards with film-forming coatings or a non-film-forming coating were exposed outdoors during 3 years. Crack development and the mass of the boards were recorded during this period. Heartwood and sapwood samples showed no differences in MC. Thus, a coating seems to reduce the differences in water sorption behaviour that is present in uncoated heartwood and sapwood spruce. The reduction is probably related to wetting properties and different sorption mechanisms, involving free and bond water diffusion. However, the low-density samples had significantly higher $\mathrm{MC}$ levels than the high-density samples. The high-density samples with a non-film-forming coating showed a higher number of cracks than those with lower density. Furthermore, sapwood samples had a remarkably high number of cracks when compared to the corresponding heartwood samples, despite a similar density and MC.
\end{abstract}

Keywords: Exterior wood coatings, Alkyd, Acrylic, Water-borne coating, Growth ring width permeability, Weathering

\section{Introduction}

Low levels of and variation in moisture content $(\mathrm{MC})$ are key factors for a long service life of coated wood products in exterior use. It is well known that different wood characteristics, for example, wood density and the presence of heartwood tissues, affect water sorption in wood [1]. However, in the field of wood coatings research, previous studies have mainly focused on the properties and behaviour of the coatings and have only considered evaluations of different combinations of wood substrates to a limited degree [2-6]. Still, the wood substrate constitutes a major part of the coated wood product.

\footnotetext{
${ }^{*}$ Correspondence: tinh.sjokvist@Inu.se

${ }^{1}$ Department of Forestry and Wood Technology, Linnaeus University, SE-351 95 Växjö, Sweden

Full list of author information is available at the end of the article
}

However, some have highlighted the role of the substrate for coated wood. Van Meel et al. [7] indicated that the reduction in water sorption depends on the unique combination of wood and coating. Dark red meranti, along with pine, was found to have a higher reduction in water sorption when coated with a solvent-borne system, while spruce had a similar reduction in water sorption independent of whether a solvent-borne or a water-borne coating system was used. Similar observations have also been presented by De Meijer [8] who concluded that the "service life of a coating during outdoor weathering depends... on properties of the coating, the wood itself and the conditions during exposure".

Most of the exterior coating systems on the market are so-called film-forming coatings. Such coatings are mostly based on an acrylic-, alkyd- or acrylic-alkyd-based resin. In Sweden, a popular alternative is the traditional calcimine coating system (i.e. "rödfärg" based on wheat flour 
with a small amount of linseed oil and some mineral additives). The calcimine system belongs to the non-filmforming coatings and is known to be highly permeable with a low resistance to weather abrasions [9].

Norway spruce (Picea abies (L.) Karst.) is one of the most common species in the Nordic market for coated facades in exterior use. Studies on uncoated spruce show a difference in water sorption properties depending on parameters such as wood density, growth ring width and the presence of heartwood [10-12]. For example, uncoated heartwood spruce absorbs a smaller amount of water as compared to sapwood in a tangential direction [12-14] and in a longitudinal direction $[15,16]$. A study on the liquid water sorption levels of coated spruce [17] had findings that showed a higher MC in low-density spruce. This establishes an expectation that heartwood tissues have a similar influence on water sorption in coated and uncoated wood. Especially, since a coating does not change the equilibrium moisture content (EMC) in wood, it only delays the sorption rate [18]. EMC is the moisture level where the water uptake and release in the wood are equal. There are, however, fewer studies on the variation in $\mathrm{MC}$ of outdoor-exposed coated spruce subjected to both liquid water (precipitation) and humidity variations. Additionally, the weathering of wood often leads to crack formation, especially in the outer layers of the wood, due to photochemical (i.e. sun radiation) surface degradation and moisture variation $[19,20]$.

The objective of this paper was, therefore, to study the MC and crack formation of outdoor-exposed coated spruce in relation to two levels of wood density and the presence of heartwood of sapwood. This paper also examines film-forming and non-film-forming coating formulas to highlight possible interactions among woodcoating properties.

\section{Materials and methods Wood material}

Twenty-three (23) logs of Norway spruce were selected from two stands in the southern part of Sweden. At the time of felling, the sapwood border was marked on each $\log$. The logs were sawn into planks of 25 and $50 \mathrm{~mm}$ thickness. The different thicknesses were employed to achieve maximum material output from each log. The planks where dried in an industrial kiln with a maximum temperature of $70{ }^{\circ} \mathrm{C}$ to a $\mathrm{MC}$ of approximately $17 \%$ relative oven-dry basis. The dried material was downsized with a band saw to $20 \pm 2$ - $\mathrm{mm} \times 100 \pm 2$ $\mathrm{mm} \times 375 \pm 2-\mathrm{mm}$ boards (radial $\times$ tangential $\times$ longitudinal direction). The board samples were straight grained and free from dead knots, cracks and resin pockets. Next the boards were divided into the following parameters, high and low density, and heartwood and sapwood. Prior to coating, the boards were conditioned to a stable mass in a climate chamber at $20{ }^{\circ} \mathrm{C}$ and $65 \%$ relative humidity $(\mathrm{RH})$. The oven-dry density of the board samples was estimated from their mass and volume in this conditioned state, using an EMC of $12 \%$ with a standard deviation (std) of $0.5 \%$. The EMC was determined from 140 pieces of uncoated spruce (70 pieces heartwood, 70 pieces sapwood) from the same wood source as the experimental material. The 140 pieces had a density range of $313-489 \mathrm{~kg} / \mathrm{m}^{3}$ (with a mean of $388 \mathrm{~kg} / \mathrm{m}^{3}$ and a std of $68 \mathrm{~kg} / \mathrm{m}^{3}$ ). The EMC was determined by measuring the stable mass at the specified climate conditions relative to the stable ovendry mass at an oven temperature of $103{ }^{\circ} \mathrm{C}$. The estimated oven-dry density and the growth ring width of the samples are presented in Table 1.

\section{Coating}

This study used four water-borne coating systems, whereof three are film-forming coating systems and one is a non-film-forming coating system. The film-forming coatings had a basecoat of an alkyd or an alkyd-acrylicbased resin. The top coats were based on an acrylic (A), alkyd (B) or alkyd-acrylic hybrid (C) resin. The non-film-forming coating (D) was a traditional Swedish calcimine paint based on wheat flour, linseed oil and copper oxide. Combinations of the base and top coats are shown in Table 2. The colour of the coatings was red (NCS 5040-Y80R). The choice of the red colour was due to the calcimine coating only being available in a few colours with the red being the most common one. The four coatings were commercially available at the time the experiment began in 2009. The complete coating formula was unknown, and only the solvent and resin were specified.

All boards were coated on their tangential sections facing the bark side and on the radial and longitudinal sections. The tangential section facing the pith was left uncoated. Boards coated with the film-forming systems had one base layer and two top layers. The boards coated with the non-film-forming system were coated with two layers of the same calcimine formula whereof the first layer used a paint solution diluted with $10 \%$ water.

The application of the coatings was performed according to the manufacturers' recommendations regarding layers, thickness and drying. A brush was used for the application and the boards were dried between each layer at $20{ }^{\circ} \mathrm{C}$ and $65 \% \mathrm{RH}$. A total of 80 board samples were prepared, which comprised of five samples of each wood-coating combination. Prior to outdoor exposure, the samples were stored in a climate chamber at $20{ }^{\circ} \mathrm{C}$ and $65 \% \mathrm{RH}$. 
Table 1 Wood sample characteristics, $\mathrm{MC}_{\mathrm{m}}$ and crack length

\begin{tabular}{|c|c|c|c|c|c|}
\hline Wood characteristics & $\begin{array}{l}\text { Oven-dry density } \\
{\left[\mathrm{kg} / \mathrm{m}^{3]}\right.}\end{array}$ & $\begin{array}{l}\text { Growth ring width } \\
\text { [mm] }\end{array}$ & $\begin{array}{l}\mathrm{MC}_{\mathrm{m}} \\
{[\%]}\end{array}$ & $\begin{array}{l}\text { Crack length year } \\
2012[\mathrm{~mm}]\end{array}$ & Replicate number \\
\hline \multicolumn{6}{|l|}{ Coating $A$} \\
\hline \multicolumn{6}{|l|}{ Low-density } \\
\hline Heartwood & $329(18)$ & $8.0(1.9)$ & $17.6(0.7)$ & 0 & $1-5$ \\
\hline Sapwood & $372(23)$ & $5.0(0.7)$ & $17.3(0.4)$ & 0 & $41-45$ \\
\hline \multicolumn{6}{|l|}{ High-density } \\
\hline Heartwood & $440(29)$ & $2.8(0.8)$ & $16.0(0.2)$ & 0 & $21-25$ \\
\hline Sapwood & $480(35)$ & $1.8(0.8)$ & $16.2(0.2)$ & 0 & $61-65$ \\
\hline \multicolumn{6}{|l|}{ Coating B } \\
\hline \multicolumn{6}{|l|}{ Low-density } \\
\hline Heartwood & $327(14)$ & $7.8(2.2)$ & $18.3(0.5)$ & 0 & $6-10$ \\
\hline Sapwood & $336(9)$ & $5.4(1.5)$ & $19.0(0.9)$ & 0 & $46-50$ \\
\hline \multicolumn{6}{|l|}{ High-density } \\
\hline Heartwood & 446 (39) & $3.2(1.6)$ & $17.2(0.3)$ & 0 & $26-30$ \\
\hline Sapwood & $488(53)$ & $1.8(0.4)$ & $17.4(0.5)$ & 0 & $66-70$ \\
\hline \multicolumn{6}{|l|}{ Coating $C$} \\
\hline \multicolumn{6}{|l|}{ Low-density } \\
\hline Heartwood & $332(17)$ & $9.0(1.9)$ & $18.3(0.5)$ & 0 & $11-15$ \\
\hline Sapwood & $371(44)$ & $6.8(1.3)$ & $18.2(1.2)$ & 0 & $51-55$ \\
\hline \multicolumn{6}{|l|}{ High-density } \\
\hline Heartwood & $457(62)$ & $2.6(1.3)$ & $16.8(0.5)$ & 0 & $31-35$ \\
\hline Sapwood & $493(48)$ & $2.4(0.5)$ & $16.5(0.7)$ & 0 & $71-75$ \\
\hline \multicolumn{6}{|l|}{ Coating D } \\
\hline \multicolumn{6}{|l|}{ Low-density } \\
\hline Heartwood & $326(17)$ & $9.4(0.9)$ & $21.9(1.0)$ & $373(87)$ & $16-20$ \\
\hline Sapwood & 347 (34) & $6.2(1.9)$ & $22.4(1.7)$ & $575(587)$ & $56-60$ \\
\hline \multicolumn{6}{|l|}{ High-density } \\
\hline Heartwood & $431(44)$ & $3.8(2.0)$ & $20.4(0.5)$ & 905 (338) & $36-40$ \\
\hline Sapwood & $471(43)$ & $1.6(0.9)$ & $20.5(0.5)$ & 2359 (667) & $76-80$ \\
\hline
\end{tabular}

Mean values of five replicates with standard deviation in parenthesis. Topcoats A-D: coating systems described in Table 2 . $M C_{m}=$ the mean value of the measurements during the period September 2009-August 2012. Crack lengths counted when wider than $0.2 \mathrm{~mm}$

Table 2 Description of the four coating systems

\begin{tabular}{lll}
\hline Coatings & Basecoat & Top coat \\
\hline A & Alkyd & Alkyd-acrylic hybrid, 2 layers \\
B & Alkyd-acrylic & Acrylic, 2 layers \\
C & Alkyd & Alkyd, 2 layers \\
D & Calcimine (10\% diluted & Calcimine, 1 layer \\
& with water) & \\
\hline
\end{tabular}

\section{Exposure}

The board samples were exposed outdoors facing south for a 3-year period beginning in June 2009. The exposure site was Asa research station, $40 \mathrm{~km}$ north of Växjö, Sweden. The samples were placed vertically on hooks approximately $60 \mathrm{~cm}$ above ground, at a $45^{\circ}$ angle to the south. A small plastic bar supported the samples from behind. No roof or wall covered the replicates.

\section{Evaluation}

Approximately, every other month beginning in September 2009, the mass of the samples was recorded with an accuracy of $0.1 \mathrm{~g}$. The moisture content was determined relative to the oven-dried mass. The presence of cracks was evaluated annually in June counting the length $(\mathrm{mm})$ of cracks wider than $0.2 \mathrm{~mm}$. A steel ruler and feeler gauge were used to measure the length and thickness of the cracks.

\section{Data analysis}

The interpretation of measurement data from multiple occasions is somewhat limited using two-dimensional statistical methods. Therefore, as a complementary 
method, the so-called principal component analysis (PCA) [21] was applied to interpret the data to describe the most pronounced differences between the sample groups.

The PCA simultaneously analyses multiple measurements of each replicate and recalculates the data from the original variable coordinates into new coordinates (i.e. principal components (PC)) for increased clarity of possible differences in the data [22]. The PCA in this study recalculates the $\mathrm{MC}$ values of multiple occasions into a score plot with the first two principal components (PC1 and PC2).

A score plot illustrates any correlations between the samples. Replicates with similar data are closely located in groups or trends on the $\mathrm{PC} 1$ and $\mathrm{PC} 2$ coordinate planes. A linear regression model with variables according to the following equation was additionally used to compare the normalised linear coefficients among the variables under study, that is,

$$
\mathrm{MC}=\mathrm{MC}_{\mathrm{mT}}+X k+F,
$$

where $X$ variable, $k$ linear coefficient and $F$ error factor for the parameter. $\mathrm{MC}_{\mathrm{mT}}$. is the average of $\mathrm{MC}_{\mathrm{m}}$ of the total population $(i=80)$, defined according to the following equation:

$$
\mathrm{MC}_{\mathrm{mT}}=\left(\sum_{1}^{i} \mathrm{MC}_{\mathrm{m} i}\right) / 80,
$$

where $i$ replicate number, in total $80 . \mathrm{MC}_{\mathrm{m} i}$ in the following equation is the average $\mathrm{MC}$ of each replicate $(i)$ including the MC of all measured occasions $(n=15)$ over a subsequent time period, or

$$
\mathrm{MC}_{\mathrm{m} i}=\left(\sum_{1}^{n} \mathrm{MC}_{n}\right) / 15,
$$

where $n$ is the nth occasion of measured MC over a subsequent time period. $\mathrm{MC}_{\mathrm{m}}$ is the general term for $\mathrm{MC}_{\mathrm{m} i}$ when no specific replicate is mentioned. The PCA was performed using Simca 13.0 and the linear regression with Modde 9.1 from Umetrics. An additional one-way analysis of variance (ANOVA) with a Tukey test on the $M_{m}$ was performed using the software program IBM SPSS statistics 24 .

\section{Results and discussion}

As presented in Table 1, the $\mathrm{MC}_{\mathrm{m}}$ was significantly lower for the samples with a film-forming coating than the samples with a non-film-forming coating. A similarly lower result of the film-forming coatings is also presented in Fig. 1a, which shows the MC fluctuations of the samples with the film-forming coatings (as an average of all samples with coating systems A, B and C) and with the non-film-forming coating (as an average of all samples with coating system D). All samples followed the variation in ambient RH and precipitation (Fig. 1b), but the curves of the two film-forming categories diverged at higher $\mathrm{MC}$ values and cohered at lower values. The higher $\mathrm{MC}$ of the samples with a non-film-forming coating confirms the higher moisture permeability of such coating, resulting in faster water sorption during periods with high precipitation and RH and likewise, faster desorption during periods of drier weather. Figure 2 shows boxplots with the median $\mathrm{MC}_{\mathrm{m}}$ values of each woodcoating combination. The results in the boxplot further support the higher permeability of the non-film-forming coating.

Figure 3 presents the average MC of the samples with a film-forming coating. The influence of density is pronounced in the figure. As can be seen, the low-density wood displayed larger $\mathrm{MC}$ changes compared to the high-density wood. Figure 4 presents the MC fluctuations of the corresponding samples with the non-film-forming coating (D). A similar pattern in MC variations' relative density was observed for samples with a calcimine coating. The deviation in $\mathrm{MC}$ between high- and low-density samples with a non-film-forming coating was larger than those of samples with a film-forming coating.

Figure 5 presents the linear coefficient ( $k$ value) of the wood and coating parameters, relative to the $M C_{m}$ of the total replicates $\left(\mathrm{MC}_{\mathrm{mT}}\right), R^{2}=0.42, Q^{2}=0.86 . R^{2}$ is the coefficient of determination and $Q^{2}$ is the predictive ability of the model. A negative $k$ value means that the parameter is likely to result in a lower $\mathrm{MC}_{\mathrm{m}}$, and the opposite for a positive value. The $k$ value confirms previous results, showing that all three film-forming coatings ( $\mathrm{A}, \mathrm{B}$ and $\mathrm{C}$ ) had a negative value and led to a lower $\mathrm{MC}_{\mathrm{m}}$, while the non-film-forming coating (D) had a positive value and a higher $\mathrm{MC}_{\mathrm{m}}$.

Furthermore, the $k$ value supports the results from Figs. 3 and 4, with a positive value for low-density wood and a negative value for high-density wood ( $95 \%$ significance). However, the $k$ value of the parameters of heartwood and sapwood had no significant effect on the $\mathrm{MC}_{\mathrm{m}}$.

It seems like the variation in MC of coated spruce is more related to wood density than to heartwood and sapwood characteristics, and the influence of density is independent of the coating permeability. Low-density spruce with larger lumens and thin cell walls facilitates an increased diffusion of water through the wood structure $[23,24]$, which is also likely to increase MC fluctuations in coated low-density wood. It is, therefore, suggested that the wood characteristics such as density and growth ring width impact the water sorption behaviour of coated spruce both in terms of seasonal MC fluctuations and 

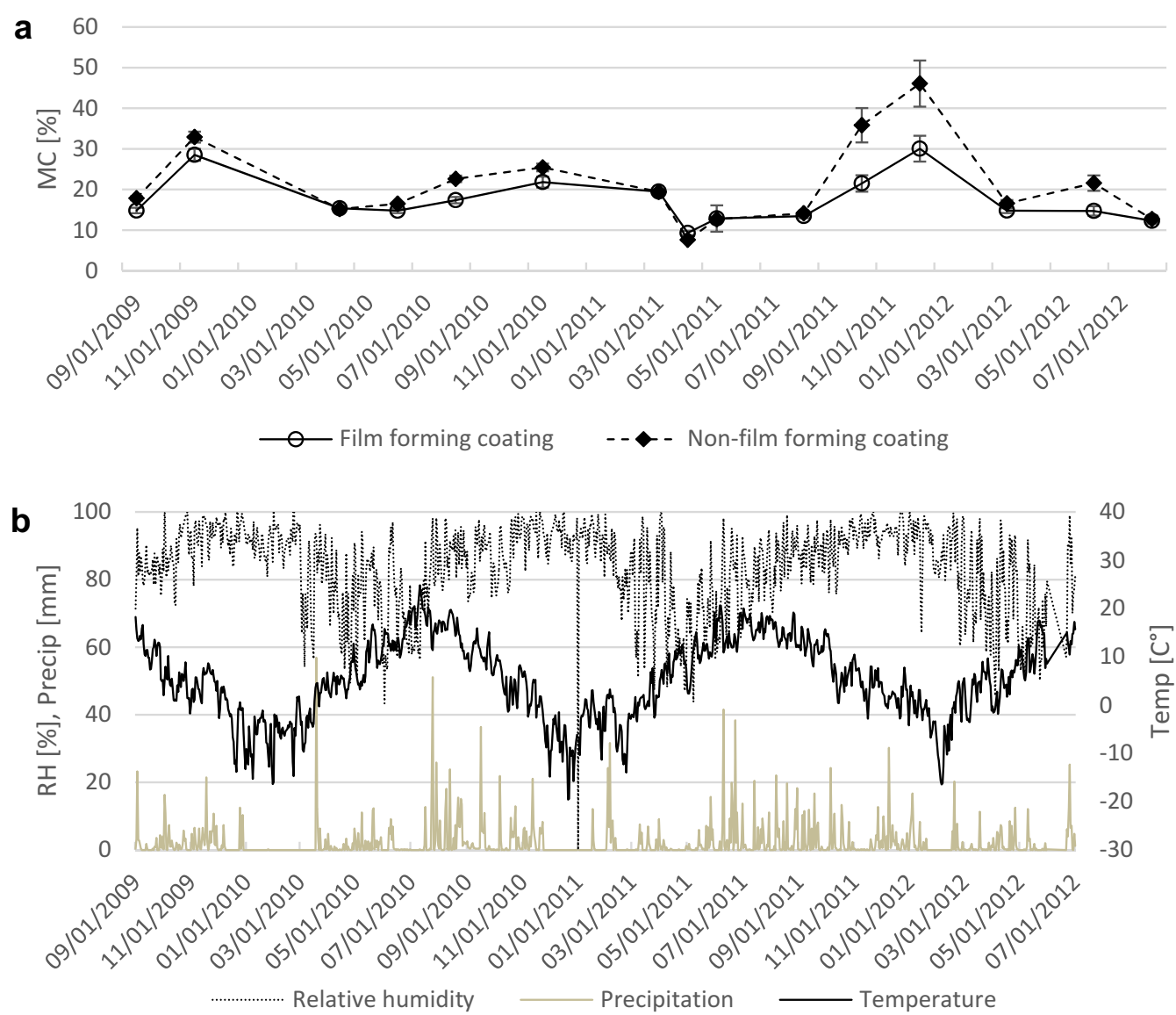

Fig. 1 a MC fluctuation for samples with the film-forming coatings (average of A, B and C) and the non-film-forming coating (D). The error bars represent the standard deviation of the values. b Relative humidity $(\mathrm{RH})$, temperature and precipitation. A-D: coating systems described in Table 2

average $\mathrm{MC}$ over time $\left(\mathrm{MC}_{\mathrm{m}}\right)$. The sorption behaviour of coated spruce was furthermore similar to that of uncoated wood, which has an increased diffusion with decreased density $[12,24]$. The uncoated backside of the samples might have contributed to this similarity.

Moving to PCA, the model used all measured data along the timeline as input, $R^{2}=0.77$ and $Q^{2}=0.69$. This means that each sample contributed with multiple values that have been measured during the test period. The following score plots in Figs. 6, 7 and 8 contain the same data but are coloured according to different parameters. Figure 6 is the score plot presenting the pattern of different coatings. The figure shows a clear division of the two clusters, i.e. the film-forming $(\mathrm{A}, \mathrm{B}, \mathrm{C})$ and nonfilm-forming (D) coatings. The cluster of film-forming coatings is further separated into the different coatings. Replicates with coating B had the most positive PC2 values, followed by coatings $\mathrm{C}$ and $\mathrm{A}$ (in decreasing order). The score plot does not reveal the magnitude of $\mathrm{MC}$ relative to different variables; rather, the position of each replicate illustrates how close they are relative to others in MC. Hence, coatings A and B had the most contrasting $\mathrm{MC}$ among the film-forming coatings since they are farthest from each other as shown in Fig. 6. Next, Fig. 7 is coloured according to the parameter of high- and lowdensity wood. Like previous figures, Fig. 7 shows a separation among different groups, but in this case, the focus is on density conditions.

Comparing the pattern seen in Fig. 6 with the pattern in Fig. 7, a separation between high- and low-density wood can be seen within each cluster of film-forming and non-film-forming coatings. The third score plot, Fig. 8, illustrates the colouring related to the heartwood and sapwood characteristics. Figure 8 is the only score plot with no clear clusters of colours or pattern. Hence, the results of this work did not indicate any impact of heartwood or sapwood characteristics on the MC of coated spruce exposed to outdoor conditions. In contrast to this study, other studies have shown that uncoated heartwood spruce absorbs a lower amount of water as compared to sapwood [16, 25]. However, all the aforementioned studies are related to uncoated spruce wood. It seems that a 


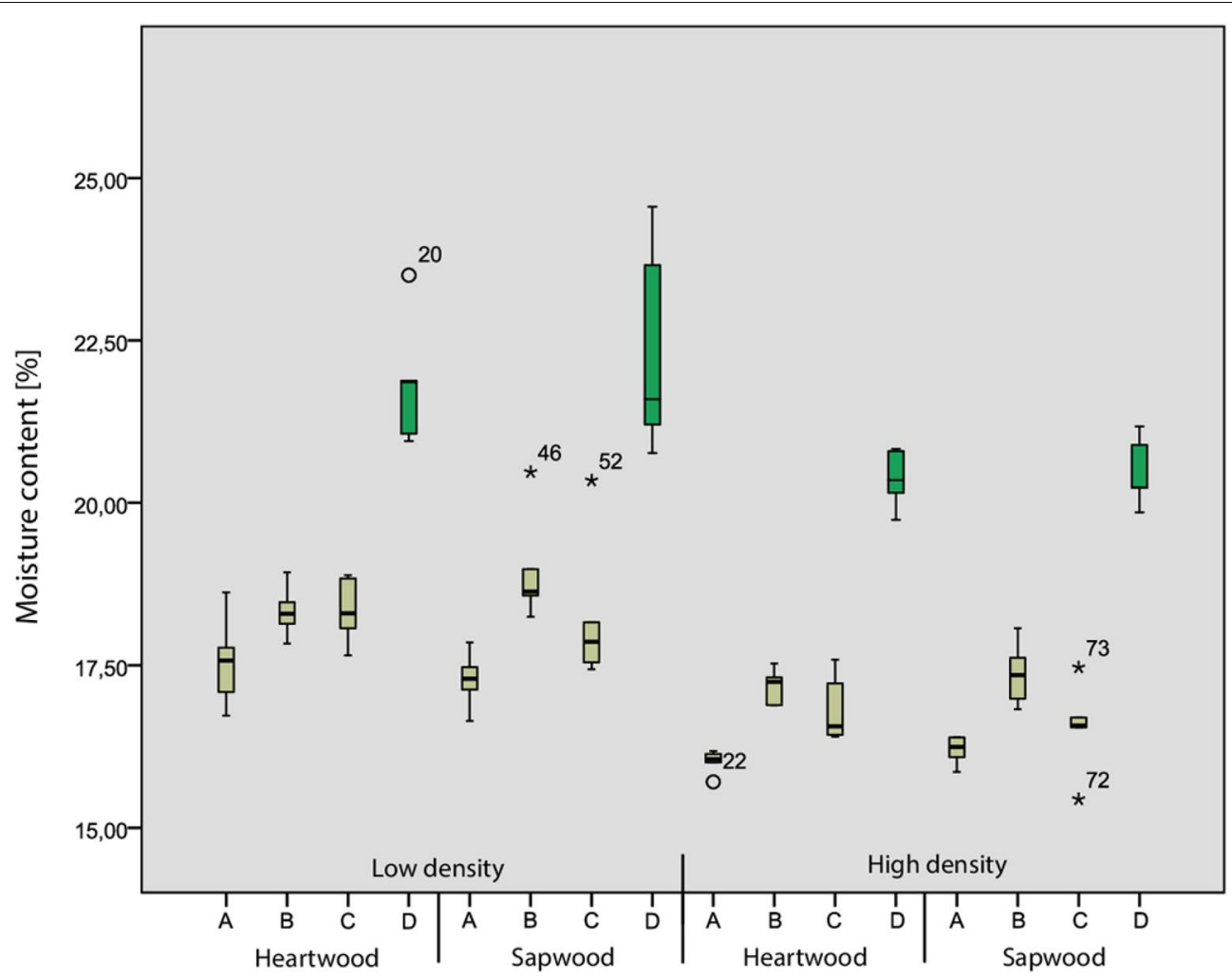

Fig. 2 Boxplot, the line in the box illustrates the median MC of five boards. The top and bottom of the box present the 25th and 75th percentiles, meaning $25 \%$ of the values are below the 25 th percentile and $25 \%$ are above the 75 th percentile. Approximately $95 \%$ of the values are expected to be within the upper and lower limits of the whiskers. The individual replicates highlighted with numbers in the graph (number 20, 22, 46, 52, 72 and 73 described in Table 1) are outliers, circles had 1.5-3 times higher or lower values than the height of the box (25th-75th percentile), and asterisks had values more than three times higher or lower. A-D: coating systems described in Table 2

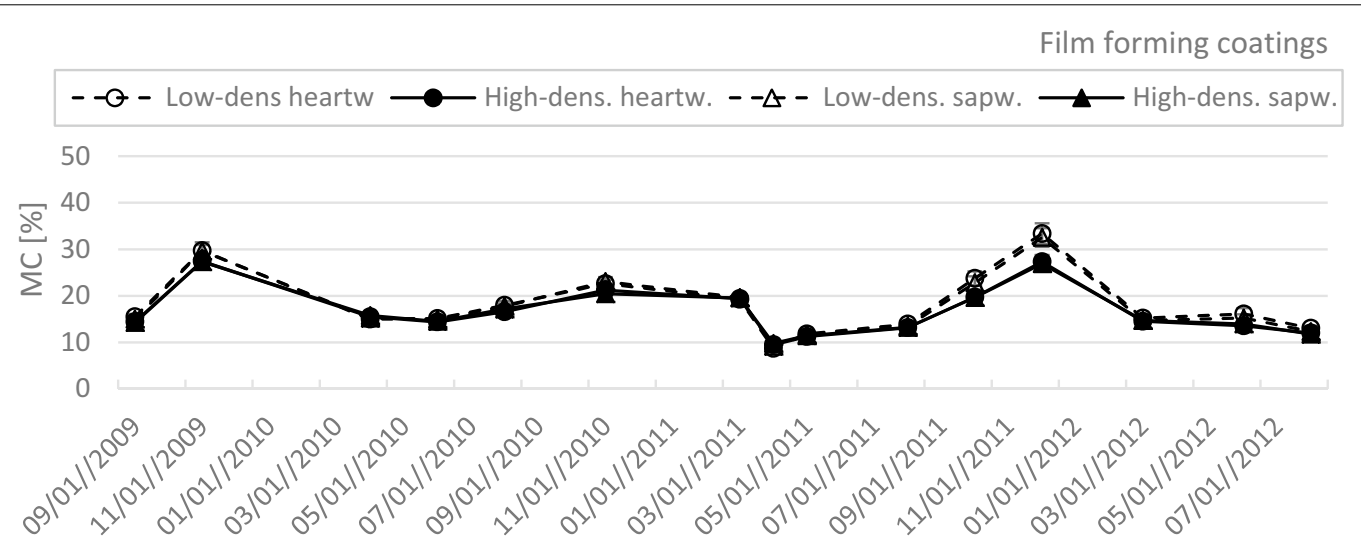

Fig. 3 MC fluctuation over 3 years for the film-forming coatings (average of A, B and C) categorised by high- or low-density heartwood or sapwood. The error bars represent the standard deviation of the values. The climate data during the period are given in Fig. $1 \mathrm{~b}$

coating system reduces such differences in water sorption behaviour between the heartwood and sapwood of spruce, which is probably related to a changed sorption mechanism involving free and bond water diffusion and wetting properties. However, more studies are needed to produce a deeper understanding of the sorption mechanisms involved for coated wood.

The ANOVA analysis with a subsequent Tukey's test showed a significantly different $\mathrm{MC}_{\mathrm{m}}$ among some of the samples. Coating B had a significantly different 


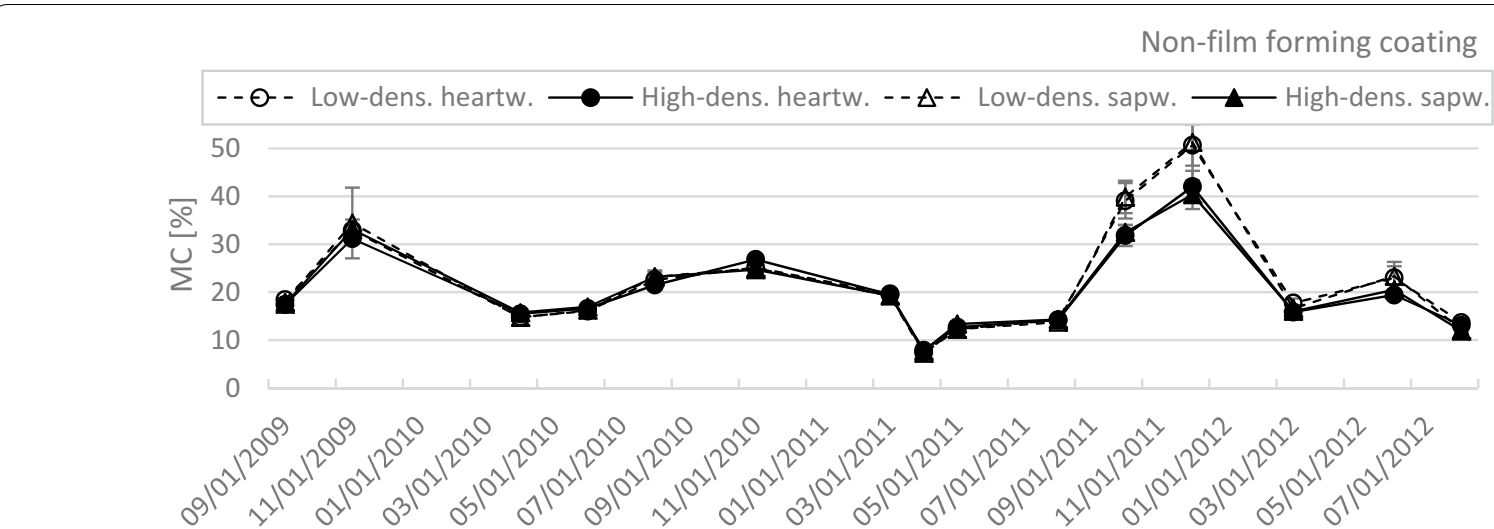

Fig. 4 MC fluctuation over 3 years for the non-film-forming coating D, categorised by high- or low-density heartwood or sapwood. The error bars represent the standard deviation of the values. The climate data during the period are given in Fig. 1b

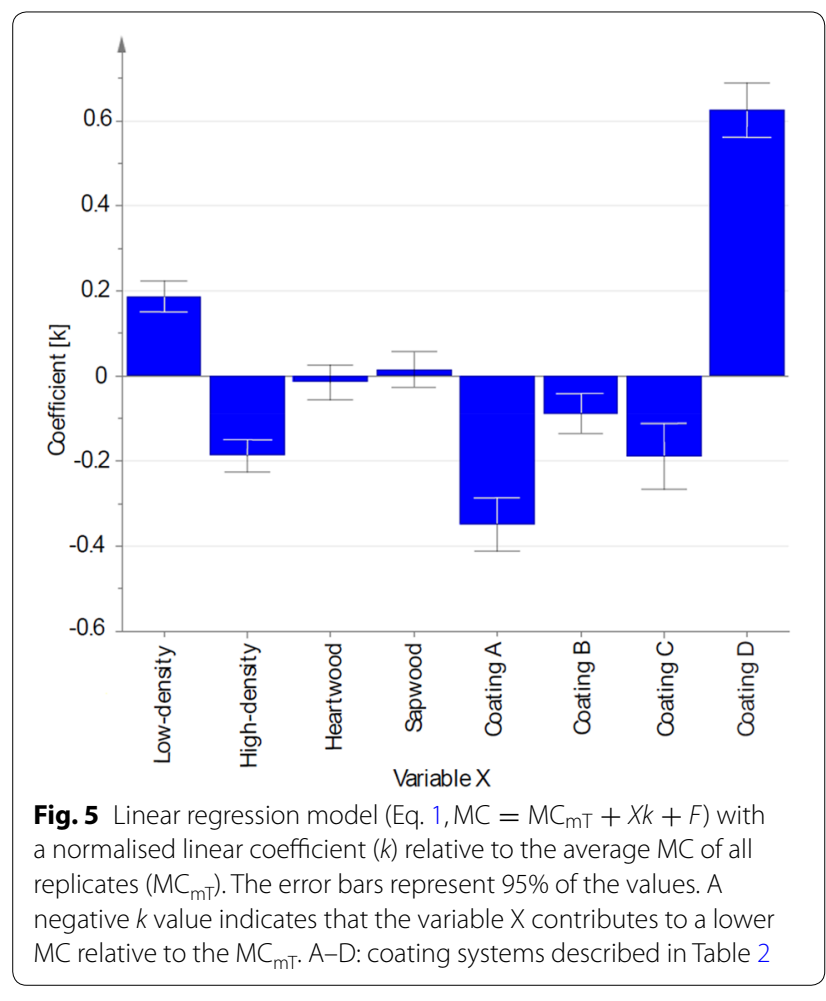

$\mathrm{MC}_{\mathrm{m}}$ between high-density heartwood and low-density sapwood. Coating $C$ had a significantly different $M_{m}$ between high-density sapwood and low-density heartand sapwood. Coating D had a significantly different $\mathrm{MC}_{\mathrm{m}}$ between low-density sapwood and high-density heart- and sapwood. However, the scattered ANOVA analysis did not show any general trends. The overall impression was that depending on the coating, different wood combinations contributed to a significantly different $\mathrm{MC}_{\mathrm{m}}$. Coatings do not change the EMC of the wood;

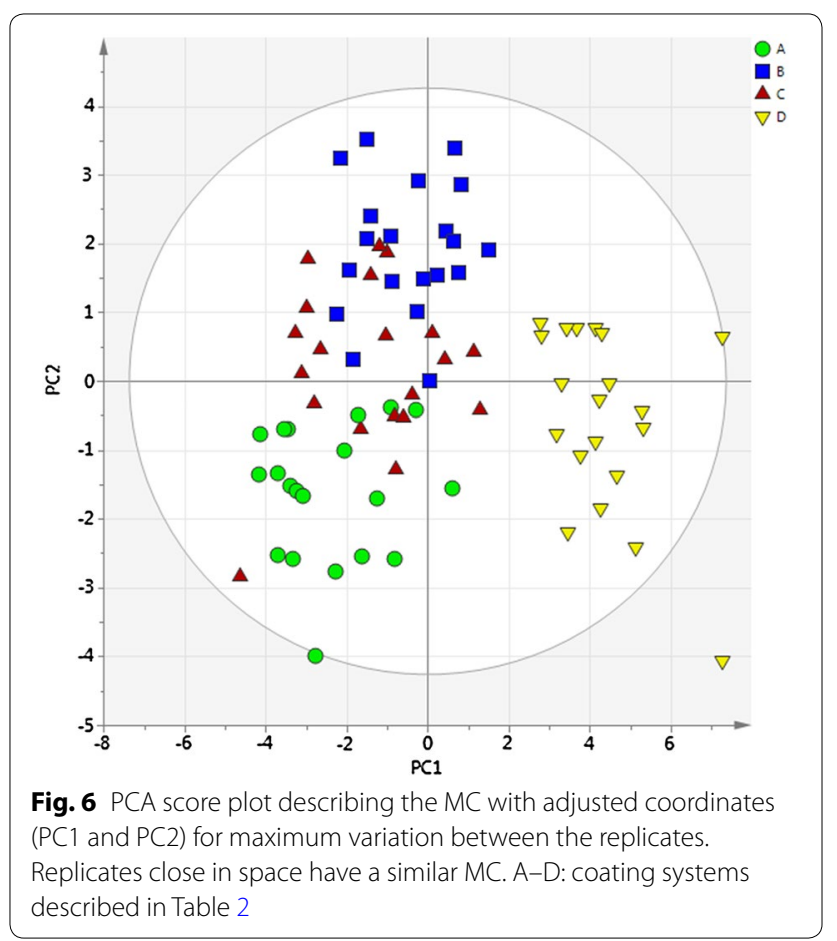

it only delays the water transportation through the film. The boundary conditions for the wood are, however, changed with a coating on the top. Hence, the scattered ANOVA suggests that the water sorption of coated wood depends not only on the sorption capacity of the wood, but on its interaction with the properties of the coating.

Table 1 also presents the length of cracks on the samples at the end of the experiment in June 2012. At this point, none of the samples with a film-forming coating had any visual signs of cracks, which can be due to the relatively low MC fluctuations during the exposure period. The first signs of cracks on the non-film-forming 


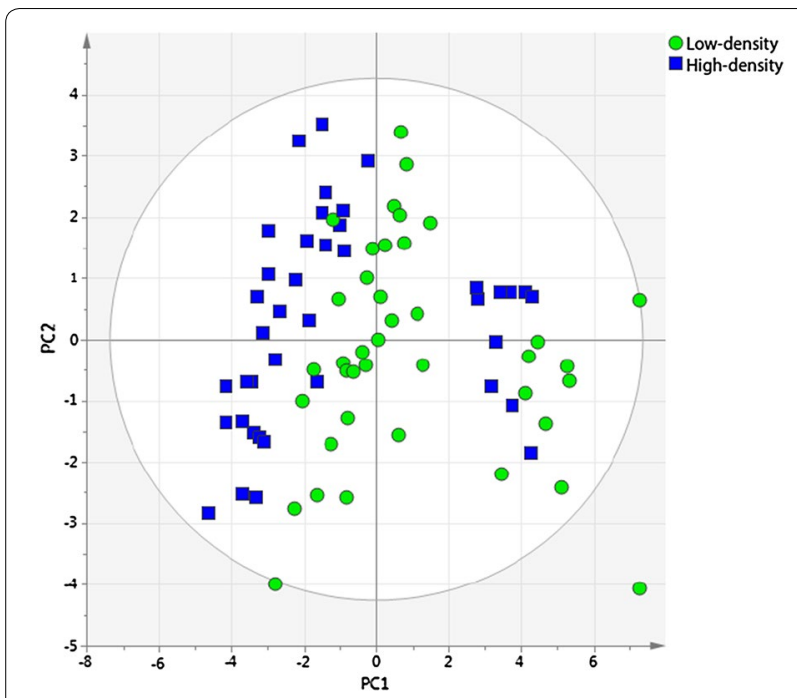

Fig. 7 PCA score plot describing the MC with adjusted coordinates (PC1 and PC2) for maximum variation between the replicates. Replicates close in space have a similar MC. The replicates are coloured according to the parameters of low- and high-density spruce

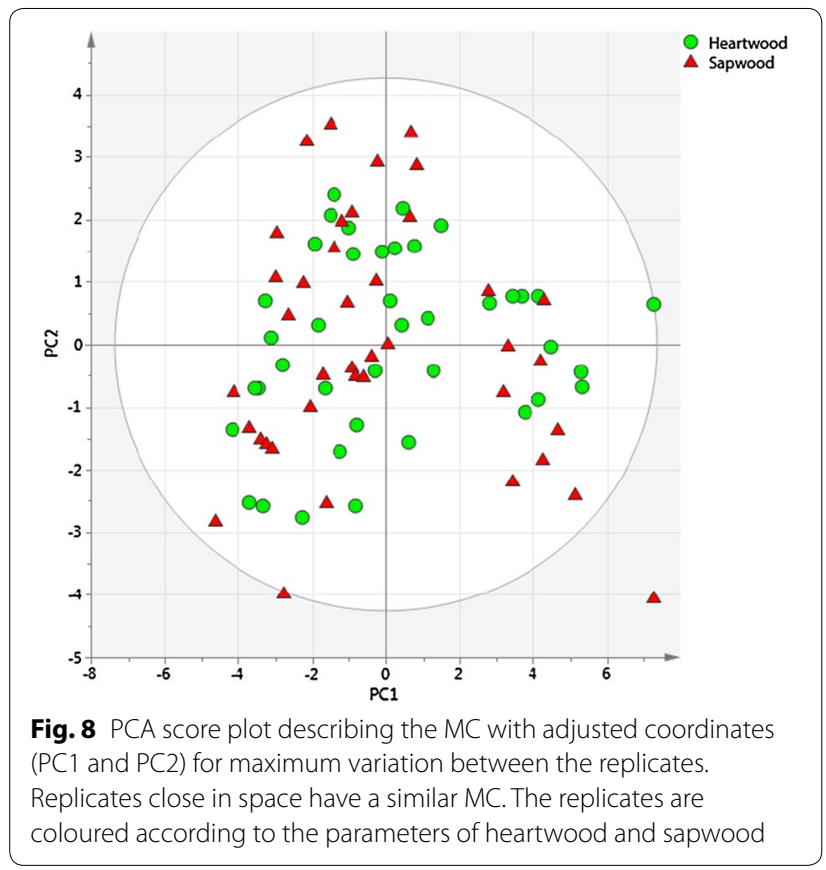

coating D appeared during the second year of exposure. As can be seen in Table 1, the high-density sapwood with coating $\mathrm{D}$ had a substantially higher crack length than the other wood samples. The dimensional movement of wood is related to the density and MC of the wood [19], and there is a tendency of a higher number of cracks on the high-density samples. However, the two samples of high-density heartwood and sapwood with coating D had a large difference in crack length despite a similar density and MC (heartwood: $\rho=431 \mathrm{~kg} / \mathrm{m}^{3}, \mathrm{MC}=20.04 \%$; sapwood: $\left.\rho=471 \mathrm{~kg} / \mathrm{m}^{3}, \mathrm{MC}=20.05 \%\right)$. Sandberg [26] studied the crack development of coated and uncoated wood and found a higher number of crack lengths on sapwood samples, irrespective of whether they were coated or not. Her finding strengthens the results in this study; however, the combination of large differences in crack formation with a similar MC was still unexpected. The differences in crack formation might be related to the moisture gradients of the coated heartwood and sapwood samples. Future studies of moisture gradients in outdoor-exposed spruce boards are, therefore, suggested to investigate if such relationship exists since this study only measured the average MC of the board. Svensson and Mårtensson [27] described, for instance, the stress formation of an uncoated sapwood board during drying, with increased drying stress at the surface when the board reached zero moisture gradient. Growth ring orientation also contributes to differences in crack development. For example, radially sawn wood with vertical growth rings shows less crack developments, especially when compared to flat sawn wood with horizontal growth rings [28]. The wood samples in this work had the same type of growth ring orientation (horizontal).

\section{Conclusions}

The samples coated with a non-film-forming coating (D) had a faster water uptake and release than the samples coated with a film-forming coating (A, B and C). The larger variations of $M C$ confirm a higher permeability in a non-film-forming coating.

Coated heartwood and sapwood showed no significant differences in $\mathrm{MC}$, as opposed to the behaviour of uncoated spruce. This lack of difference in sorption behaviour indicates that a coating system changes the sorption difference that is seen in uncoated spruce heartwood and sapwood, even for highly permeable coatings. This is probably related to the different sorption mechanism involved in free and bond water diffusion and wetting properties. However, more studies are needed for a deeper understanding of the change in conditions when a coating is involved.

There were, however, a significantly faster MC increase and decrease for the low-density spruce samples as compared to high-density samples, independent of the coating permeability. The overall findings suggest that wood characteristics such as density impact the water sorption of coated spruce both in terms of seasonal $\mathrm{MC}$ variations and average $\mathrm{MC}$ over time $\left(\mathrm{MC}_{\mathrm{m}}\right)$.

Samples with the non-film-forming coating (D) developed cracks during the exposure time. High wood 
density influenced to higher degree the number of cracks as compared to samples with a lower density. In the case of the high-density samples, sapwood had a remarkably higher number of cracks (i.e. crack length) despite a similar density and average $\mathrm{MC}$ over time $\left(\mathrm{MC}_{\mathrm{m}}\right)$. The cause behind the observed difference is not clear, but a future study about the moisture gradients of coated heartwood and sapwood panels is suggested to further investigate the observation.

\begin{abstract}
Abbreviations
MC: moisture content; EMC: equilibrium moisture content; Std: standard deviation; RH: relative humidity; PCA: principal component analysis; $\mathrm{PC} 1$ and PC2: principal components 1 and 2; $k$ : linear coefficient; $M_{C_{m}}$ : average $M C$ of each replicate including all measured occasions; ANOVA: analysis of variance.
\end{abstract}

\section{Acknowledgements}

The authors greatly acknowledge Jonaz Nilsson who prepared the samples and supported data collection, the Swedish infrastructure of Ecosystem Science (SITES) who provided the test field and Mikael Bergström who advised the statistical work.

\section{Authors' contributions}

TS interpreted the results and wrote the majority of the manuscript. ÅB designed the experiment, collected the results and supervised the writing. MW interpreted the results and wrote a part of the manuscript. All authors read and approved the final manuscript.

\section{Funding}

This work was supported by the Swedish paint and adhesives association, and The Bridge, a strategic collaboration between Linnaeus University and IKEA of Sweden. This work was also financially supported by the Swedish Research Council Formas (Project EnWoBio 2014-172).

\section{Availability of data and materials}

The datasets used and analysed during the current study are available from the corresponding author on reasonable request.

\section{Competing interests}

The authors declare that they have no competing interests.

\section{Author details}

1 Department of Forestry and Wood Technology, Linnaeus University, SE-351 95 Växjö, Sweden. ${ }^{2}$ Department of Civil and Architectural Engineering, Building Materials, KTH Royal Institute of Technology, Stockholm, Sweden.

Received: 20 June 2019 Accepted: 30 August 2019

Published online: 17 September 2019

\section{References}

1. Kollmann FFP, Côté WA (1968) Principles of wood science and technology, vol solid wood. Springer-Verlag, Berlin

2. Ahola P, Derbyshire H, Hora G, de Meijer M (1999) Water protection of wooden window joinery painted with low organic solvent content paints with known composition. Part 1. Results of inter-laboratory tests. Eur J Wood Prod 57:45-50

3. De Meijer M, Militz H (2001) Moisture transport in coated wood. Part 2: influence of coating type, film thickness, wood species, temperature and moisture gradient on kinetics of sorption and dimensional change. Eur J Wood Prod 58:467-475

4. Lu Y, Xiao S, Gao R, Li J, Sun Q (2014) Improved weathering performance and wettability of wood protected by $\mathrm{CeO}_{2}$ coating deposited onto the surface. Holzforschung 68:345-351
5. Grüll G, Truskaller M, Podgorski L, Bollmus S, De Windt I, Suttie E (2013) Moisture conditions in coated wood panels during 24 months natural weathering at five sites in Europe. Wood Mat Sci Eng 8:95-110

6. Ekstedt J (2003) Influence of coating system composition on moisture dynamic performance of coated wood. J Coat Technol 75:27-37

7. Van Meel PA, Erich SJF, Huinink HP, Kopinga K, de Jong J, Adan OCG (2011) Moisture transport in coated wood. Prog Org Coat 72:686-694

8. De Meijer M (2001) Review on the durability of exterior wood coatings with reduced VOC-content. Prog Org Coat 43:217-225

9. Mårdh P-A (1990) Röda stugor: En bok om rödfärgens egenskaper, om recept och tillverkning, om husen och traditionen, om rödfärg idag. Byggförlaget, Stockholm

10. Bergström M, Blom $\AA$ (2006) Differences in properties between Norway spruce (Picea abies) heartwood and sapwood. Part 2. Vapour and Liquid permeability. Paper presented at the Wood Protection Conference, New Orleans, USA

11. Sandberg K (2009) Norway spruce heartwood: properties related to outdoor use. Dissertation, Luleå University of Technology, Sweden

12. Sivertsen MS, Vestøl GI (2010) Liquid water absorption in uncoated Norway spruce (Picea abies) claddings as affected by origin and wood properties. Wood Mat Sci Eng 5:181-193

13. Blom Å, Johansson J, Sivrikaya H (2013) Some factors influencing susceptibility to discoloring fungi and water uptake of Scots pine (Pinus sylvestris), Norway spruce (Picea abies) and Oriental spruce (Picea orienta(is). Wood Mat Sci Eng 8:139-144

14. Sjökvist T, Wålinder MEP, Blom $\AA$ (2018) Liquid sorption characterisation of Norway spruce heartwood and sapwood using a multicycle Wilhelmy plate method. Int Wood Prod J 9:58-65

15. Sandberg K (2006) Modeling water sorption gradients in spruce wood using CT scanned data. NZ J For Sci 36:347-364

16. Fredriksson M, Lindgren $O$ (2014) End grain water absorption and redistribution in slow-grown and fast-grown Norway spruce (Picea abies (L.) Karst.) heartwood and sapwood. Wood Mat Sci Eng 8:245-252

17. Sivertsen MS, Flæte PO (2012) Water absorption in coated Norway spruce (Picea abies) cladding boards. Eur J Wood Prod 70:307-317

18. Williams RS, Jourdain C, Daisey GI, Springate RW (2000) Wood properties affecting finish service life. J Coat Technol 72:35-42

19. Stamm AJ (1964) Wood and cellulose science. Ronald Press, New York

20. Evans PD, Urban K, Chowdhury MJA (2008) Surface checking of wood is increased by photodegradation caused by ultraviolet and visible light. Wood Sci Technol 42:251-265

21. Joliffe IT (1986) Principal component analysis. Springer, New York

22. Tharwat A (2016) Principal component analysis-a tutorial. Int J Appl Pattern Recognit 3:197-240

23. Siau JF (1984) Transport processes in wood. In: Timell TE (ed) Springer series in wood science. vol 2. Springer-Verlag, Berlin; New York. https:// doi.org/10.1007/978-3-642-69213-0

24. Skaar C (1988) Wood-water relations. In: Timell TE (ed) Springer series in wood science. Springer-Verlag, New York

25. Sandberg K, Salin J-G (2012) Liquid water absorption in dried Norway spruce timber measured with CT scanning and viewed as a percolation process. Wood Sci Technol 46:207-219

26. Sandberg K (2008) Degradation of Norway spruce (Picea abies) heartwood and sapwood during 5.5 years' above-ground exposure. Wood Mat Sci Eng 3:83-93

27. Svensson S, Mårtensson A (2002) Simulation of drying stresses in wood Part II. Convective air drying of sawn timber. Eur J Wood Prod 60:72-80

28. Sandberg D (2005) Distortion and visible crack formation in green and seasoned timber: influence of annual ring orientation in the cross section. Eur J Wood Prod 63:11-18

\section{Publisher's Note}

Springer Nature remains neutral with regard to jurisdictional claims in published maps and institutional affiliations. 